\title{
PREVALENCE OF UNDER NUTRITION AND ASSOCIATED FACTORS AMONG PEOPLE OF OLD AGE IN DEBRE MARKOS TOWN, NORTHWEST ETHIOPIA, 2015
}

\author{
Z.K. Adhana ${ }^{1}$, G.H. Tessema², G.A. Getie ${ }^{3}$
}

\begin{abstract}
Background: Malnutrition is defined as a disproportion of nutrients caused by either an excess intake of nutrients or a nutritional deficit. One of the most common nutritional problems in older people (aged 60 years and over) is under nutrition. Worldwide studies revealed that the prevalence of under nutrition in people of old age is high. Objective: To assess the prevalence of under nutrition and its associated factors among old people in Debre Markos town, Northwest Ethiopia, 2015. Methods and materials: A cross sectional study design was conducted among 423 study subjects of old age in Debre Markos town from August 4 to August 30, 2015. Primary data was collected using a pre tested Mini Nutritional Assessment Short-Form (MNA-SF) screening tool and structured questionnaires by trained data collectors. The data that was collected was entered and cleaned using EpiData version 3.1 statistical software then exported to the SPSS version 20 statistical package for further data analysis. Descriptive statistics of frequency, tables and graphs were used and summary measures were calculated to determine the prevalence of under nutrition. The data was also used to describe the distribution of the independent variables among study subjects. Bivariate and multivariate logistic regression models were utilized to calculate crude and adjusted odds ratios in order to identify factors associated with under nutrition of study participants at 0.05 level of significance. Result: The prevalence of under nutrition among study participants was found to be $22.7 \%$ (95\% CI 18.7-26.7). A number of independent variables have a significant association with under nutrition, including gender (females (AOR 7.95 95\% CI $(2.86,22.08)$ ), age (Oldest Old and Middle Old, (AOR=3.45 95\% CI $(1.44,8.26)$ and $(\mathrm{AOR}=5.25,95 \% \mathrm{CI}(2.48,11.13)$ respectively), marital status (widowed elderly individuals (ARO 3.29 95 \% CI $(1.54,7.06)$ ), individuals with eating difficulty (AOR $10.7395 \%$ CI $(4.49,25.63)$, individuals with vision problems (AOR 5.6795 $\%$ CI $(2.80,11.48)$ and meal frequency (ARO $6.7195 \%$ CI $(3.31,13.63)$. Conclusion and recommendation: Prevalence of under nutrition among study participants was $22.7 \%$. Gender, age, marital status, eating difficulty, visual problems and meal frequency were found to be independent determinant factors of under nutrition among study subjects. The government, family members and other stakeholders should give more attention to older individuals especially older females.
\end{abstract}

Key words: Under nutrition, old age, prevalence, mini nutritional assessment

\section{Introduction}

Malnutrition is a general term that refers to both under-nutrition and over-nutrition. Under-nutrition is due to inadequate food intake, dietary imbalances, and deficiencies of specific nutrients (1). Undernourishment is common in older persons. Nutritional deficiencies in older persons have serious negative consequences which can increase morbidity and mortality, hospitalization, development of ulcer and infections (2). Involuntary weight loss can result in a reduction in the ability to care for oneself, loss of mobility and independence and a

1. Missionaries of Charity - Ethiopia, Psychologist and program coordinator, Debremarkos, Ethiopia; 2. Department of Public Health, College of Health Sciences, Debre Markos University, Debre Markos, Ethiopia; 3. Department of Nursing, College of Health Sciences, Debre Markos University, Debre Markos, Ethiopia.

Corresponding Author: Zinabu Kebede Adhana, Missionaries of Charity - Ethiopia, Psychologist and program coordinator, Debremarkos, Ethiopia, alamata2007@ yahoo.com

Received October 5, 2018

Accepted for publication October 15, 2018 poorer quality of life (3).

The elderly population is growing worldwide. There were approximately 810 million persons aged 60 years and over in the world in 2012 and this number is projected to grow to more than 2 billion by 2050 (6). In 2014 , the annual growth rate for the population aged 60 years and older will be almost triple the growth rate for the population as a whole (7) one out of every nine persons in the world is aged 60 years or over (6). In 2014, about two thirds of the world's population aged 60 years and older lived in the less developed regions (7). By 2050, one out of every five persons is projected to be in that age group and one in 16 persons in Africa (6). In general, the number of older person is increasing rapidly and unexpectedly in all parts of the world. Although aging is evolving fast in the more developed regions, the less developed regions will over a much shorter period of time (6).

In Ethiopia, due to serious shortage of data, it is difficult to provide detailed analysis about the socio- 
economic conditions of older persons (4). Even though it is difficult to provide detailed analysis about the old age population of Ethiopia, the UN report shows that the population aged $60+$ is growing rapidly (6).

Older adults are at the greatest risk for becoming undernourished. Undernourishment may result in impairment, lowered resistance to infection; poor wound healing, and prolonged hospitalization with increased morbidity and mortality (8). Additionally, medical co-morbidities and a host of other factors, such as economic, geographic, and psychosocial concerns, can also affect diet behaviors and thus nutritional status (9).

Under nutrition among old age is a substantial problem globally. World-wide, the older population is increasing, and with it, the prevalence of under nutrition. The prevalence of under nutrition is undeniably high; worldwide the overall prevalence is $22.6 \%$ (15). The prevalence of under nutrition in older African men (9.5-36.1\%) and women (13.1-27\%) (16). In Ethiopia, the prevalence of under nutrition in old age people is remains high, as a study conducted in Gondar revealed that the prevalence of under nutrition among old age people was $21.9 \%$ (17).

More generally, the study of under nutrition in the $60+$ age group in Ethiopia has been neglected. Most of the studies conducted on under nutrition in Ethiopia focus on mothers and children; producing more data related to the nutritional status of those within the old age group will fill the existing knowledge gap.

\section{Objectives}

* To determine the prevalence of under nutrition among old age people in Debre Markos town.

* To identify associated factors with under nutrition of old age people in Debre Markos town.

\section{Method and material}

\section{Study design}

A community based cross-sectional study design was conducted.

\section{Study area and period}

The study was conducted in Debre Markos Town. Debre Markos is the town of East Gojjam Administrative Zone; which is located in the Northwest of Addis Ababa at a distance of $300 \mathrm{Kms}$. With regard to the population of the town it is estimated to be 107684 of which 57791 are females and 49893 are males (34). Out of this total population the number of old age population is estimated at 3000 and from this estimated total number 1800 old age individuals (1276 females and 524 males) are officially registered (35). The data was collected from August 4, 2015 to August 30, 2015.

\section{Source population}

All old people who are living in Debre Markos town.

\section{Study population}

All old individuals who are officially registered in Debre Markos town.

\section{Inclusion criteria}

All old individuals greater than or equal to sixty years old, who are already registered in Social and Labor Office and were available during data collection period, were included in this study.

\section{Exclusion criteria}

Individuals who are unable to respond due to critical illness during data collection were excluded from this study.

\section{Sample size determination}

The sample size was calculated using single population proportion formula considering $50 \%$ prevalence of under nutrition, 0.05 level of type one error, 0.05 marginal error at $95 \%$ level of confidence and adding $10 \%$ non-response rate. The final sample size was 423 .

\section{Sampling procedure}

Primarily the total number of households was identified through reviewing records from the social and labor office. All individuals were then framed using their particular code number of the house and their name. From this list, sampled individuals were drawn through systematic random sampling technique from already registered individuals. The total number of registered individuals were $(\mathrm{N}=1800)$ and then calculated sampling fraction (Kth). A lottery method was used to get the first sampled individual from 1-4 sampling intervals. With a random start of two every fourth individual was included in to the study.

\section{Variables of the study}

Under nutrition of old age individuals is considered to be the dependent variable while socio-demographic variables (age, sex, marital status, ethnicity, family number, educational status, occupation, income), medical condition, smoking, feeding frequency (one times, two times and three times per day), food-cooking style (self, spouse, children, and/or maid) and feeding mode (unable 
PREVALENCE OF UNDER NUTRITION AND ASSOCIATED FACTORS AMONG PEOPLE OF OLD AGE IN DEBRE MARKOS TOWN, NORTHWEST ETHIOPIA, 2015.

to eat without assistance, self-fed with some difficulty, self-fed without any problem) are independent variables.

\section{Operational definition}

Old age people: those individuals aged $\geq 60$ years old. Young old: individuals' age group from $60-74$ years old. Aged: individuals' age group from $75-84$ years old. Oldest old: individuals' age group from $85+$ years old (37). Nutritional status: for this study individuals who had $>7$ score were considered as having normal nutritional status (by merging normal nutrition and risk of under nutrition) and who had a score $<=7$ considered as having under nutrition. Dementia status: for this study, according to 6 CIT - King shill Version 2000, Dementia screening tool individuals who had a score of between 0 and 7 was considered as having normal score (no dementia), where as individuals who had a score of between 8 and 10 were considered as having mild dementia and individuals who had a score of between 10 and 28 were considered as having severe dementia.

\section{Data collection instrument and measurement}

The data was collected from participants' by the means of structured questionnaire to address sociodemographic, socioeconomic, health and individual life style old age individuals and Mini Nutritional assessment Short - Form (MNA-SF) was used to assess nutritional status of old age individuals. The MNA-SF screening tool has five questionnaires and one anthropometric measuring tool on food intake, weight loss, mobility, psychological stress or acute disease, presence of dementia or depression and body mass index (BMI). When height and/or weight cannot be assessed, an alternate scoring for BMI is then included in the measurement of calf circumference.

\section{Data processing and analysis}

The data was entered into EpiData version3.1 software. It was then exported to SPSS version 20 for further data analysis. Binary logistic regression analysis was the fitted model to distinguish the effect of each independent variable on the dependent variable. Variables had a p-value $<0.2$ in the bivariate analysis was transferred to multiple variable analyses to control confounding variables. Those independent variables with a p-value of less than 0.05 with their respective adjusted odds ratio at $95 \%$ confidence interval was considered as having statistical association.

\section{Ethical considerations}

Ethical clearance was obtained from Debre Markos University health science college ethical review committee; further permission letters were also secured from each formal sector institutions in Debre Markos town. Informed consent was obtained from each study participants. Privacy and confidentiality was maintained.

\section{Result and Discussion}

\section{Socio demographic and economic characteristics of respondents:}

Of the study participants, three-fourth $(77 \%, \mathrm{n}=324)$ of them were females. The median age of the respondents was 72 years, ranging from 60 to 90 years old. More than half $(57 \%, \mathrm{n}=242)$ of the respondents were married while few $(4 \%, \mathrm{n}=19)$ were either separated or single in their marital status. The most $(94 \%, \mathrm{n}=399)$ were Amhara in their ethnicity. About 47\% ( $n=200)$ of the respondents responded that they could not read and write while $46 \%$ $(n=195)$ could read and write only by their educational status. Regarding to occupation, $62 \%(\mathrm{n}=262)$ were house wife while few $4 \%,(n=15)$ were merchants. The majority $(62 \%, \mathrm{n}=263)$ of the respondents had a monthly income 567 or less ETB. While $34 \%(n=142)$ and $4 \%(n=18)$ had 568-1033 and 1034 or greater ETB, respectively (Table 1).

\section{Medical conditions and life style characteristics of the study participants}

\section{Medical conditions}

Among total study participants more than half $(58 \%, \mathrm{n}=245)$ responded as they had faced one or more medical illness at least once in their older life time. Of those that faced medical illness, visual problems were the most frequently self-reported illness, as reported by $29 \%(\mathrm{n}=122)$ of the respondents, meanwhile the least frequently faced illness was diabetes mellitus $(4 \%, \mathrm{n}=17)$ (Fig1).

\section{Life style characteristics of study participants}

All of the study participants responded that they did not smoke. The majority $(80 \%, \mathrm{n}=338)$ of the respondents were responded as their children cooking their meals and the least number of respondents $(2 \%, n=10)$ indicated that they had a maid cooking for them. Regarding mode of feeding, most $(96 \%, \mathrm{n}=408)$ of the study participants, responded as they could self-feed without any problem. In addition nearly three-fourth $(74 \%, \mathrm{n}=311)$ of the respondent replied as they have had a frequency of 3 or more meals per day (Table 2). 
Table 1

Socio-demographic and Socioeconomic characteristics of elderly people in Debre Markos town, Northwest

Ethiopia, 2015

\begin{tabular}{|c|c|c|c|}
\hline Variables & & Number & Percent \\
\hline \multirow[t]{2}{*}{ Sex } & Female & 324 & 77 \\
\hline & Male & 99 & 23 \\
\hline \multirow[t]{3}{*}{ Age } & Young old & 231 & 54 \\
\hline & Aged & 75 & 18 \\
\hline & Oldest old & 117 & 28 \\
\hline \multirow[t]{4}{*}{ Marital status } & Married & 242 & 57 \\
\hline & Divorced & 41 & 10 \\
\hline & Widowed & 121 & 29 \\
\hline & Single/ separated & 19 & 4 \\
\hline \multirow[t]{2}{*}{ Ethnicity } & Amhara & 399 & 94 \\
\hline & Oromo/Tigre/Agew/other & 24 & 6 \\
\hline \multirow[t]{2}{*}{ Family size } & $<4$ & 227 & 54 \\
\hline & $>=4$ & 196 & 46 \\
\hline \multirow[t]{3}{*}{ Educational status } & Cannot read and write & 200 & 47 \\
\hline & Read and write only & 195 & 46 \\
\hline & Primary and above & 28 & 7 \\
\hline \multirow[t]{6}{*}{ Occupation } & House wife & 262 & 61.9 \\
\hline & Merchant & 15 & 3.6 \\
\hline & Non-government employee & 27 & 6.4 \\
\hline & Self employed & 81 & 19.1 \\
\hline & Pension & 38 & 9 \\
\hline & $<=568$ & 263 & 62.2 \\
\hline \multirow[t]{2}{*}{ Monthly income } & $568-1033$ & 142 & 33.5 \\
\hline & $>=1033$ & 18 & 4.3 \\
\hline
\end{tabular}

Figure 1

Self-reported medical condition of the study participants in Debre Markos town, Northwest Ethiopia, 2015

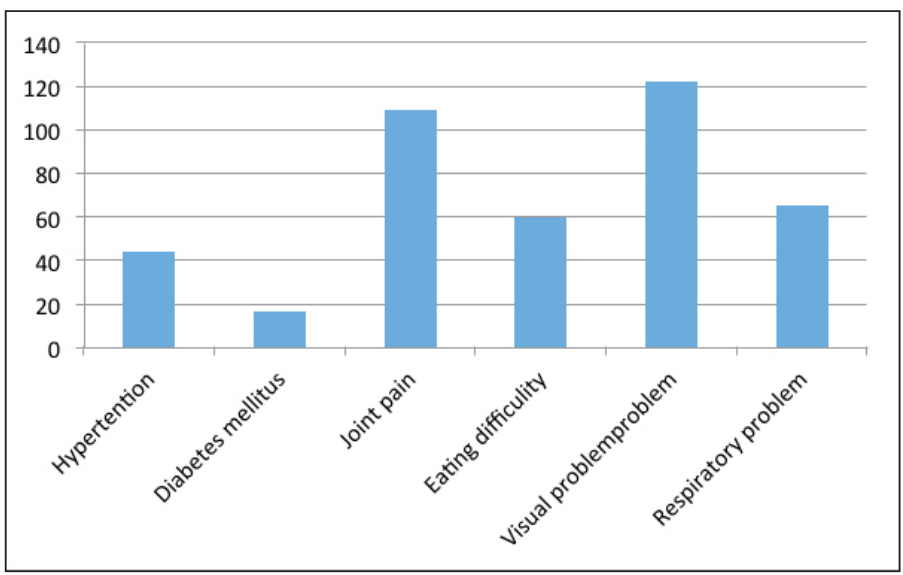

\section{Nutritional status of the study participants}

The nutritional status of the study participants were determined using the four level (0-3) multiple items (6) score scaling techniques of the MNA-SF screening tool. The tool is statistically reliable with the Cronbach score of $\alpha=0.74$. Based on the assessment, the average item score was found to be $1.84 \pm 0.76$ standard deviation with the variance of 0.58 . Of the respondents, $22.7 \% \quad(n=96)$ were found to be under nutrition with a cumulative score of seven or less assessment items. The remaining $77.7 \%$ $(n=327)$ were found to be well-nourished with cumulative score of greater than seven nutritional assessment items (see summary based on item score Table 3).

Table 2

Life style characteristics of study participants in Debre Markos town, Northwest Ethiopia, 2015

\begin{tabular}{llll}
\hline & Response & Number & Percent \\
\hline Who is your food cooker? & Self-cooking & 56 & 13 \\
& Spouse & 19 & 5 \\
& Child & 338 & 80 \\
& Maid & 10 & 2 \\
What is your mode of & $\begin{array}{l}\text { Self-fed with some } \\
\text { difficulty } \\
\text { feeding? }\end{array}$ & 15 & 4 \\
& $\begin{array}{l}\text { Self-fed without any } \\
\text { problem }\end{array}$ & 408 & 96 \\
& $<3$ meal frequency & 112 & 26 \\
Meal frequency & $>=3$ meal frequency & 311 & 74 \\
\hline
\end{tabular}

Table 3

A Mini Nutritional Assessment (MNA-SF) item score among study participants in Debre Markos town, Northwest Ethiopia, 2015

\begin{tabular}{lccccc}
\hline Items & \multicolumn{6}{c}{ Number of Respondents } & with & item score of \\
\hline & 0 & 1 & 2 & 3 & Total \\
Food intake decline & - & 97 & 326 & - & 423 \\
Weight loss & 6 & 151 & 8 & 258 & 423 \\
Current mobility & 6 & 5 & 412 & - & 423 \\
Acute illness & 102 & 321 & - & - & 423 \\
Presence of dementia & 38 & 26 & 359 & - & 423 \\
BMI/calf & 91 & 85 & 113 & 134 & 423 \\
\hline
\end{tabular}

Factors associated with nutritional status of old age individuals

Gender was found to be a significant variable; females were nearly eight times more likely to suffer from under nutrition as compared to males (AOR 7.95 95\% CI (2.86, 22.08). Age was also found to be associated with under nutrition in elderly people. The oldest old and middle old $((\mathrm{AOR}=3.45$ 95\% CI $(1.44,8.26),(\mathrm{AOR}=5.25,95 \% \mathrm{CI}(2.48$, 11.13) respectively) were more likely to suffer from under nutrition than younger old people.

Regarding marital status, widowed individuals were 3.3 times more likely to suffer from under nutrition 
PREVALENCE OF UNDER NUTRITION AND ASSOCIATED FACTORS AMONG PEOPLE OF OLD AGE IN DEBRE MARKOS TOWN, NORTHWEST ETHIOPIA, 2015.

Table 4

Bi-variable and multiple variable logistic regressions for nutritional status among participants in Debre Markos town, Northwest Ethiopia, 2015

\begin{tabular}{|c|c|c|c|c|c|c|}
\hline \multirow[t]{2}{*}{ Variable categories } & & \multicolumn{5}{|c|}{ Undernourished } \\
\hline & & Yes & No & COR 95\% CI & AOR 95\% CI & P-value \\
\hline \multirow[t]{2}{*}{ Sex } & Female & 81 & 243 & $1.87(1.02,3.42)$ & $7.95(2.86,22.08)$ & $0.001^{*}$ \\
\hline & Male & 15 & 84 & 1 & & \\
\hline \multirow[t]{3}{*}{ Age category } & Young old & 22 & 209 & 1 & & \\
\hline & Aged & 26 & 49 & $5.04(2.64,9.63)$ & $3.45(1.44,8.26)$ & $0.005^{*}$ \\
\hline & Oldest old & 48 & 69 & $6.61(3.73,11.73)$ & $5.25(2.48,11.13)$ & $0.001^{*}$ \\
\hline \multirow[t]{4}{*}{ Marital status } & Married & 29 & 213 & 1 & & \\
\hline & Divorced & 10 & 31 & $2.37(1.05,5.33)$ & $2.58(0.93,7.17)$ & 0.07 \\
\hline & Widowed & 51 & 70 & $5.35(3.15,9.09)$ & $3.29(1.54,7.06)$ & $0.002^{*}$ \\
\hline & Single/Separated & 6 & 13 & $3.39(1.19,9.61)$ & $1.68(0.43,6.61)$ & 0.46 \\
\hline \multirow[t]{2}{*}{ Family size } & $<4$ & 64 & 163 & $2.01(1.25,3.24)$ & $1.53(0.71,3.26)$ & 0.27 \\
\hline & $>=4$ & 32 & 164 & 1 & & \\
\hline \multirow[t]{5}{*}{ Occupation } & Merchant & 2 & 13 & 1 & & \\
\hline & NGO employee & 3 & 24 & $0.81(0.12,5.49)$ & $0.54(0.04,6.51)$ & 0.62 \\
\hline & Self-employed & 33 & 48 & $4.47(0.95,21.12)$ & $1.59(0.20,12.56)$ & 0.66 \\
\hline & Housewife & 46 & 216 & $1.38(0.30,6.34)$ & $0.24(0.03,1.85)$ & 0.17 \\
\hline & Pension & 12 & 26 & $3.00(0.58,15.44)$ & $2.67(0.30,23.27)$ & 0.37 \\
\hline \multirow[t]{3}{*}{ Education } & Cannot read and write & 61 & 139 & $3.66(1.06,12.57)$ & $3.35(0.72,15.67)$ & 0.12 \\
\hline & Can read and write & 32 & 163 & $1.64(0.47,5.75)$ & $3.46(0.73,16.34)$ & 0.12 \\
\hline & Primary and above & 3 & 25 & 1 & & \\
\hline \multirow[t]{3}{*}{ Monthly income } & $=<567$ & 72 & 191 & $1.89(0.53,6.70)$ & $0.31(0.05,1.99)$ & 0.22 \\
\hline & $568-1033$ & 21 & 121 & $0.87(0.23,3.26)$ & $0.54(0.08,3.52)$ & 0.52 \\
\hline & $=>1034$ & 3 & 15 & 1 & & \\
\hline \multirow[t]{2}{*}{ Hypertension } & Yes & 5 & 39 & $0.41(0.16,1.06)$ & $0.35(0.11,1.11)$ & 0.07 \\
\hline & No & 91 & 288 & 1 & & \\
\hline \multirow[t]{2}{*}{ Eating difficulty } & Yes & 29 & 31 & $4.13(2.33,7.32)$ & $10.73(4.49,25.63)$ & $0.001^{*}$ \\
\hline & No & 67 & 296 & 1 & & \\
\hline \multirow[t]{2}{*}{ Visual problem } & Yes & 61 & 61 & $7.60(4.61,12.53)$ & $5.67(2.80,11.48)$ & $0.001^{*}$ \\
\hline & No & 35 & 266 & 1 & & \\
\hline \multirow[t]{2}{*}{ Respiratory problem } & Yes & 21 & 44 & $1.80(1.01,3.21)$ & $1.56(0.65,3.71)$ & 0.32 \\
\hline & No & 75 & 283 & 1 & & \\
\hline \multirow[t]{4}{*}{ Who is your food cooker? } & Self-cooking & 8 & 48 & $0.49(0.23,1.09)$ & $0.62(0.22,1.72)$ & 0.35 \\
\hline & Spouse & 2 & 17 & $0.35(0.08,1.55)$ & $0.37(0.034 .61)$ & 0.44 \\
\hline & Child & 85 & 253 & 1 & & \\
\hline & Maid & 1 & 9 & $0.33(0.04,2.65)$ & $0.32(0.02,4.61)$ & 0.40 \\
\hline \multirow[t]{2}{*}{ What is your mode of feeding? } & Self-fed with some difficulty & 7 & 8 & $3.14(1.11,8.88)$ & $1.26(0.25,6.31)$ & 0.80 \\
\hline & Self-fed without any problem & 89 & 319 & 1 & & \\
\hline \multirow[t]{2}{*}{ Meal frequency } & $<3$ meal frequency & 55 & 57 & $6.35(3.87,10.43)$ & $6.71(3.31,13.63)$ & $0.001^{*}$ \\
\hline & $>=3$ meal frequency & 41 & 270 & 1 & & \\
\hline
\end{tabular}

* Statistically Significant 
(AOR $3.2995 \%$ CI $(1.54,7.06)$. Elderly people who had difficulty eating were 10.73 times more likely to suffer from under nutrition (AOR $10.7395 \%$ CI $(4.49,25.63$ ). Also elderly participants with vision problems were 5.67 times more likely to suffer from under nutrition (AOR $5.6795 \%$ CI $(2.80,11.48)$. Finally, elderly individuals who had meal less than three times per a day were 6.71 times more likely to suffer from under nutrition (AOR 6.7195 \% CI $(3.31,13.63)$ (Table 4).

\section{Discussion}

In this study the prevalence of under nutrition among old age individuals was found $22.7 \%$ of those sampled. This finding was similar with studies done in Gondar, Ethiopia $(21.9 \%)$ and Rural Bangladesh $(26 \%)(17,20)$ and lower prevalence compared to those reported in Bogota, Colombia (4.58\%) and Sargodha city, Pakistan (5.53\%) (22, 27). These differences could be created by the variation of geographic, socioeconomic and inclusion or exclusion criteria of the study participants.

Regarding the association between sex and under nutrition, this study revealed a significant difference between females and males. Females were nearly eight times more likely to be undernourished than males. This was supported by studies done in Gondar, Ethiopia which shows that females were three times more likely to be undernourished than males and in Calcutta, India which reported that females were vulnerable $(8.9 \%)$ than males $(4.9 \%)$ to be undernourished $(17,21)$. The reason female older individuals are more vulnerable for under nutrition could be explained by the fact that the older population is predominantly female and tend to live longer than men (26) and it may also be due to the fact that older females still remain the care takers of their grandchildren and they receive less than the care necessary for themselves. Another possible implication could be due to cultural influence. However, the present study contradicts with a study done in Sargodha city, Pakistan which reported under nutrition was more prominent in older males $(3.16 \%)$ as compared to the older females $(2.37 \%)$ (27). This difference could also be created by the variation of geographic and socioeconomic status of the study participants.

Age is found to have a significant association with under nutrition in older people. Under nutrition was most common in the aged (75-84 years) and oldest old (85 years and above) age groups compared with young old age group. This finding was similar to a study done in Gondar, Ethiopia which states that oldest old and middle old were more likely to be undernourished than young old people (38.1 and 14.6) respectively (17). As age increases the risk of under nutrition increases. This might be due to the natural aging process accompanied by physiological changes which can negatively impact nutritional status and cause inadequate nutrition $(11,18)$.

Marital status was one of the factors that affected the nutritional status of elderly individuals. Individuals who are widowed/ widower were 3.3 more likely to be undernourished compared to those who are married. This finding was supported by study done in Portugal which was assessed the nutritional status of older adult in the community and reported that widowed individuals were 6.73 times more likely to be undernourished than non-widowed older individuals (29). The reason could be that being alone as a result of the death of one of the mates decreases social relations and economic deficiencies (18). These changes may cause inadequate nutrition. The loss of one's mate may also be associated with loss of motivation to prepare and eat food. In this case, grief is considered a heavy burden that contributes to reduction of food intake which thereby increases risk of undernourishment.

Eating difficulties, there was found to be a significant association with under nutrition. The participants who had reported eating problem were nearly eleven times more likely to be undernourished. Eating difficulties may be a result of oral problems such as decrease in number of teeth, usage of dental facilities, which leads to problems in chewing food. This particular problem relies on the presence of adequate teeth or dentures, and saliva flow $(10,18)$. This could be a barrier to the intake of different nutritional elements and make the important meal situation problematic in an older individuals and lead to the need for several adaptations with regard to food choice and preparation (33) and which may lead eventually under nutrition.

With regard to visual problem, there was significant association with elderly under nutrition. According to this study old age people with visual problem were nearly six times more likely to be undernourished compared to those elderly without visual problem. This could be due to older individual with visual impairment may not be able to prepare, shop, and cook and/or properly select their food. Moreover, if they live with their children, they may not receive enough attention and/or they may be served food that is either low in quality or in quantity that can affect nutritional status.

Finally, meal frequency was a factor which showed significant association with elderly under nutrition $(<\mathrm{P} 0.001)$. Elderly participants who were served less than three meals per day were more likely to be under nourished than those who were served three or more meals per day. This result was similar with a study done in Bangladesh $(\mathrm{P}<0.001)(20)$. This change in meal pattern may occur with the result of natural aging, physiological or physical changes, and/or it may be due to a lack of food.

\section{Conclusion and Recommendation}

This study revealed that the prevalence of under nutrition among study participants is high in Debre Markos town Northwest, Ethiopia. It was also 
indicated that sex, age, marital status, eating difficulty, visual problems and meal frequency were found to be independent determinant factors of under nutrition among old age individuals, especially among female individuals of old age. It is very important to merge nutritional management with clinical practice for elderly individuals and that consideration is given to individuals who have visual problems and eating difficulties. Researchers should conduct further comprehensive nutritional assessments of the elderly, and in addition, intervention programs supported by the government which target the elderly under nutrition should be strengthened.

\section{Limitation of the Study}

The limitation of this study was; it focused only on the urban elderly individuals and might not represent the rural residents.

Acknowledgment: We would like to thank Debre Markos University and GAMBY College of Medical Sciences for giving us the chance to do this study. We would like to acknowledge the data collectors and study participants.

Authors' contribution: All authors designed the proposal, oversaw the measurement tool, participated in data collection arrangement and supervision, checked the collected data, analyzed and interpreted it. They also checked the final report of the research.

Conflict of interest: All the authors in this study declare neither financial nor non-financial competing interests.

Ethical Standard: This study was approved by Debre Markos University health science college human research ethical committee and complied with current laws governing ethics in research

\section{References}

1. Katherine MURPHY. Malnutrition in the community and hospital setting. The patient association. August 2011, 54

2. Karen E. CHARLTON, Monica FERREIRA, and Jean M FOURIE. Chapter 8, Nutrient Requirements and Factors Affecting Nutritional Status in Older Adults. In: Norman J TEMPLE and Nelia P STEYN. Community Nutrition Textbook for Developing Countries. 2008, 159

3. Anne SCHNEYDER. Malnutrition and Nutritional Supplements. Australian prescriber. August 2014, V. 37: No. 4

4. United Nations Department of Economic and Social Affairs. Population aging and development. 2012, available at: http/ / www.unpopulation.org

5. United Nation (UN): Department of Economic and Social Affairs Population Division Concise Report on the World Population Situation in 2014: A Concise Report, 2014: 24

6. Ethiopian Ministry of Labor and Social Affairs: General condition of the elderly: 2011, available at http://www.molsa.gov.et/English/SWD/Pages / SituationofElderly.aspx

7. Kathy FLAMMOND. Chapter 14, Dietary and Clinical Data Assessment. In: Yvonne ALEXOPOULOS, Kristin HEBBERD and Heather BAYS. Krause's Food and Nutrition therapy. USA: International Edition: 2008, 12 editions, 383

8. Connie Watkins BALES and Mary Ann JOHNSON. Chapter 56, Nutrition in Older adults'. In: A. Catharine ROSS, Benjamin CABALLERO, Robert J. COUSINS, Katherine L. TUCKER and Thomas R. Ziegler. Modern Nutrition in Health and Disease. USA: Williams and Wilkins, a Wolters Kluwer business, 2014, Eleventh edition, 745

9. Nestle Nutrition institute MNA ${ }^{\circledR}$, Mini Nutritional Assessment. The problem malnutrition: available at http//www.mna-elderly.com/the_problem malnutrition.html

10. Karen E. CHARLTON and Donald ROSE. Nutrition among Older Adults in Africa; the Situation at the Beginning of the Millennium. J. Nutr., 2001, 131, $2424 S$

11. Tessfamichael D, Gete AA, Wassie MM. High Prevalence of Under nutrition among Elderly People in Northwest Ethiopia: A Cross Sectional Study. J Nutrition Health Food Sci. 2014,2(4):1-5

12. Debre Markos University: Official Website of Debere Markos University, 2013, available at: http// web.dmu.edu.et/test-dmu-site/index.php/category.../ debre-markos

13. Debre Markos town woreda administrative women, youth and children office, 2015

14. Nigerian National Population Commission: National Population Census 1991 Analysis. The Elderly. Abuja: 2004, Volume 3.

15. Zarina Nahar KABIR, Tamanna FERDOUS, Tommy CEDERHOLM, Masuma Akter KHANAM, Kim STREATFIED and $\mathrm{A}^{\circ}$ ke WAHLIN. Mini Nutritional Assessment of rural elderly people in Bangladesh: the impact of demographic, socio-economic and health factors. Public Health Nutrition. February 2006, 9(8): 968-974

16. Diego Chavarro-CARVAJAL, Carlos Reyes-ORTIZ, Rafael Samper-TERNENT, Antonio J. ARCINIEGAS, and Carlos Cano GUTIERREZ. Nutritional Assessment and Factors Associated to Malnutrition in Older Adults: A Cross Sectional Study in Bogotá, Colombia. Journal of Aging and Health. 2015, Vol. 27(2): 304-319

17. Mondrita MAJUMDER, IndranilSaha, and Debnath CHAUDHURI. Assessment of Nutritional Risk in Community-Dwelling Older Adults (65 to 75 Years) in Kolkata, India. Journal of Nutrition in Gerontology and Geriatrics. 2014, 33:126-134

18. United Nations. Department of Economic and Social Affairs: Population Division. UN, 2013, available at: http//www.un.org/en/... / desa/population /.../pdf/.../ WorldPopulation Ageing201

19. Abdul GHANI, Sarfraz HUSSAIN, Muhammad ZUBAIR. Assessment of nutritional status of geriatrics population in Sargodha City, Pakistan. Int. J med. Appl. Health. 2013, Vol. 1: 7

20. Width MARY and Reinhard TONIA: Chapter 4, Older Adults. Clinical Dietitian's Essential Pocket Guide. USA: Lippincott Williams \& Wilkins, 2009: 1st Edition, 98

21. Emine AKSOYDAN, Turan BUZGAN, Biriz ÇAKIR and Meltem SOYLU. Old age period and nutrition. Ankara, Turkey: The Republic of Turkey Ministry of Health, November 2006, 2nd Edition (in English)

22. Ana Luísa Moreira dos SANTOS, Teresa Maria de Serpa Pinto Freitas do AMARAL, and Nuno Pedro Garcia Fernandes Bento BORGES. Undernutrition and associated factors in a Portuguese older adult community. Rev. Nutr., Campinas, maio/jun., 2015, 28(3):231-240

23. Ellie WHITNEY and Shoron Rody ROLFES: Chapter 17, Life Cycle Nutrition: Adulthood and the Later Years. Understanding nutrition. USA: Thomson Learning, Inc.,2008: Eleventh edition, 594-601

24. Maria NYBERG, Viktoria OLSSON, Zada PAJALIC, Gerd ÖRTMAN, Håkan S. ANDERSSON, Anna BLÜCHER, Karin WENDIN \& Albert WESTERGREN: Eating difficulties, nutrition, meal preferences and experiences among elderly a literature overview from a Scandinavian context: Journal of Food Research; Vol 4, No. $1 ; 2015$ 